\title{
Natural History of Multiple Sclerosis with Childhood Onset
}

\author{
Christel Renoux, M.D., Sandra Vukusic, M.D., Yann Mikaeloff, M.D., \\ Gilles Edan, M.D., Michel Clanet, M.D., Bénédicte Dubois, M.D., \\ Marc Debouverie, M.D., Bruno Brochet, M.D., Christine Lebrun-Frenay, M.D., \\ Jean Pelletier, M.D., Thibault Moreau, M.D., Catherine Lubetzki, M.D., \\ Patrick Vermersch, M.D., Etienne Roullet, M.D., Laurent Magy, M.D., \\ Marc Tardieu, M.D., Samy Suissa, Ph.D., and Christian Confavreux, M.D., \\ for the Adult Neurology Departments KIDMUS Study Group*
}

ABSTRACT

\section{BACKGROUND}

The course and prognosis of childhood-onset multiple sclerosis have not been well described.

\section{METHODS}

We used data from 13 adult neurology departments affiliated with the European Database for Multiple Sclerosis (EDMUS) network to identify a cohort of 394 patients who had multiple sclerosis with an onset at 16 years of age or younger and a comparison group of 1775 patients who had multiple sclerosis with an onset after 16 years of age. We determined the initial clinical features, the dates of disease onset, and the occurrence of outcomes, including relapse, conversion to secondary progression, and irreversible disability as measured by scores of 4 (limited walking ability but ability to walk more than $500 \mathrm{~m}$ without aid or rest), 6 (ability to walk with unilateral support no more than $100 \mathrm{~m}$ without rest), and 7 (ability to walk no more than $10 \mathrm{~m}$ without rest while using a wall or furniture for support) on the Kurtzke Disability Status Scale (range, 0 to 10; higher scores indicate more severe disability).

\section{RESULTS}

For patients with childhood-onset multiple sclerosis, the estimated median time from onset to secondary progression was 28 years, and the median age at conversion to secondary progression was 41 years. The median times from onset to disability scores of 4,6 , and 7 were 20.0, 28.9, and 37.0 years, respectively, and the corresponding median ages were $34.6,42.2$, and 50.5 years. In comparison with patients with adultonset disease, those with childhood-onset disease were more likely to be female than male (female:male ratio, 2.8 vs. 1.8), were more likely to have an exacerbating-remitting initial course ( $98 \%$ vs. $84 \%$ ), took approximately 10 years longer to reach secondary progression and irreversible disability, and reached these landmarks at an age approximately 10 years younger $(\mathrm{P}<0.001$ for all comparisons).

\section{CONCLUSIONS}

Patients with childhood-onset multiple sclerosis take longer to reach states of irreversible disability but do so at a younger age than patients with adult-onset multiple sclerosis.
From Hôpital Neurologique Pierre Wertheimer, Hospices Civils de Lyon; INSERM Unité 842; and Université Lyon 1 - all in Lyon (C.R., S.V., C.C.); Hôpital de Bicêtre, Paris Kremlin-Bicêtre, Paris (Y.M., M.T.); Hôpital Pontchaillou, Rennes (G.E.); Hôpital Purpan, Toulouse (M.C.); Hôpital Saint Julien, Nancy (M.D.); Hôpital Pellegrin, Bordeaux (B.B.); Hôpital Pasteur, Nice (C.L.-F.); Hôpital de la Timone, Marseille (J.P.); Hôpital Général, Dijon (T.M.); Hôpital de la Pitié-Salpêtrière, Paris (C.L.); Hôpital Roger Salengro, Centre Hospitalier Régional Universitaire, Lille (P.V.); Hôpital Tenon, Paris (E.R.); and Centre Hospitalier Universitaire Dupuytren, Limoges (L.M.) - all in France; University Hospital Gasthuisberg, Leuven, Belgium (B.D.); and Royal Victoria Hospital, McGill University, Montreal (C.R., S.S.). Address reprint requests to $D r$. Confavreux at Service de Neurologie A and the European Database for Multiple Sclerosis Coordinating Center, Hôpital Neurologique Pierre Wertheimer, 59 blvd. Pinel, 69677 Lyon-Bron CEDEX, France, or at christian. confavreux@chu-lyon.fr.

*The other members of the Adult Neurology Departments Kids with Multiple Sclerosis (KIDMUS) Study Group are listed in the Appendix.

N Engl J Med 2007;356:2603-13. Copyright (c) 2007 Massachusetts Medical Society. 
M

ULTIPLE SCLEROSIS GENERALLY AFfects young adults between 20 and 40 years of age. ${ }^{1}$ Onset occurs in childhood (before the age of 16 years) in 0.4 to $10.5 \%$ of cases. $^{2-11}$ There are few studies on the natural history of childhood-onset multiple sclerosis, and most of these studies describe either single cases or small series. The four largest series include no more than 200 patients each. ${ }^{12-15}$ There are still a number of unresolved issues regarding childhoodonset multiple sclerosis. The main objective of our collaborative study was to describe the natural history of the disease and determine the prognostic factors for disability in a cohort of patients with onset of multiple sclerosis before or at the age of 16 who were being seen in departments of adult neurology affiliated with the European Database for Multiple Sclerosis (EDMUS) network. Another objective was to compare the course and prognosis of childhood-onset and adult-onset multiple sclerosis.

METHODS

\section{PATIENT POPULATION, DATA COLLECTION,} AND DEFINITION OF CASES

Patients were identified from the databases of 13 French and Belgian departments of adult neurology participating in the EDMUS network..$^{16}$ Data collection in these centers began in 1976 (Lyon) and continued through 2001 (Dijon). All centers use the EDMUS software and collect uniform information about all patients with multiple sclerosis who have been examined at least once as outpatients or inpatients in the department. Information is collected by neurologists with a special interest in multiple sclerosis, in a retrospective fashion at the time of the first visit, and prospectively thereafter. The EDMUS database has been approved by the French Commission Nationale del'Informatique et des Libertés. Oral informed consent is obtained from each patient before data are entered in the database.

Patients included in the database have a diagnosis of definite or probable multiple sclerosis according to the classification of Poser et al., ${ }^{17}$ which is based on three criteria: dissemination of lesions in time (at least two distinct neurologic episodes in the course of the disease); spatial dissemination of lesions in the central nervous system, as demonstrated by clinical findings, magnetic resonance imaging, computed tomography, or testing of evoked potentials; and quan- titative or qualitative abnormalities of IgG in the cerebrospinal fluid. Cases are considered clinically definite when the first two criteria are met, regardless of the results of the cerebrospinal fluid test; laboratory-supported definite cases meet the first and third or the second and third criteria; clinically probable cases meet the first or second criterion; and laboratory-supported probable cases meet the third criterion.

We identified a cohort of patients with childhood-onset multiple sclerosis from data collected through 2003 at all 13 centers. Data on eligible patients were extracted automatically and validated with the source medical records by one of the authors. For comparison with this group, we also identified a cohort of patients with adult-onset multiple sclerosis from data collected at the Lyon center through April 1997. Data collected after April 1997 were not used because only data collected before this time had been validated from the source medical records by one of the authors. ${ }^{18-21}$ Furthermore, before April 1997 almost no patients had received currently acknowledged disease-modifying therapies, and therefore this cohort of patients with adult-onset multiple sclerosis can be regarded as essentially a naturalhistory cohort. ${ }^{18-21}$

\section{ASSESSMENT OF OUTCOMES}

Relapse and the progressive phase of multiple sclerosis were defined according to established criteria. ${ }^{16,18,22,23}$ The initial course was classified as exacerbating-remitting or progressive. The overall course was classified as relapsing-remitting, secondarily progressive, or progressive from the onset. ${ }^{16,18,23}$ Dates of onset of the disease, relapses, and conversion to the progressive phase were recorded. Symptoms were classified as isolated optic neuritis, isolated brain-stem dysfunction, isolated dysfunction of long tracts, or other symptoms or combinations of symptoms. ${ }^{16,18}$

The Kurtzke Disability Status Scale (DSS) score (range, 0 to 10, with higher scores indicating more severe disability) was recorded at each visit to determine the extent of neurologic disability. ${ }^{24,25}$ Focus was placed on scores that could be easily assigned, even retrospectively. A score of 4 indicates limited walking ability but able to walk more than $500 \mathrm{~m}$ without assistance and without resting; a score of 6 indicates the ability to walk only with unilateral support and no more than $100 \mathrm{~m}$ without resting; and a score of 7 indicates the ability to walk no more than $10 \mathrm{~m}$ without resting 
while using a wall or furniture for support. Disability was defined as irreversible when a given score persisted for at least 6 months, excluding transient worsening of disability related to relapses. ${ }^{18}$

\section{PROGNOSTIC FACTORS}

Potential prognostic factors considered were sex, age at onset of multiple sclerosis, whether the initial course of the disease was exacerbating-remitting or progressive, initial symptoms, the time interval between the first two neurologic episodes, the number of relapses during the first 2 years of the disease, and the decade of onset of multiple sclerosis.

\section{STATISTICAL ANALYSIS}

We performed descriptive analyses using the chisquare and Fisher's exact tests for categorical variables and the Student's t-test and the Wilcoxon test for continuous variables. We used the KaplanMeier method to estimate the time to secondary progression, the times to irreversible disability (DSS scores of 4, 6, and 7), and the ages at each of these outcomes. Comparisons between the childhood-onset and adult-onset cohorts were made by the log-rank test. Cox proportional-hazards models were used to identify factors associated with faster development of irreversible disability. Data from patients who had not yet reached the end point were censored at the date of their last visit. Three different time-to-event analyses were performed with three different reference times, depending on the factors under study. The first analysis was performed with the reference time defined as the onset of multiple sclerosis. To assess the prognostic value of the time between the first and the second neurologic episodes, the date of the second neurologic episode was used as the reference time. To assess the prognostic value of the number of relapses during the first 2 years of multiple sclerosis, 2 years after the onset of multiple sclerosis was used as the reference time. Statistical significance was defined by an alpha level of 0.05 . All analyses were performed with SAS software for Windows, version 8.

RESULTS

CHILDHOOD-ONSET MULTIPLE SCLEROSIS

Patient Characteristics

Among the 17,934 patients at the 13 participating centers, 394 (2.2\%) had multiple sclerosis starting at 16 years of age or younger, and 290 (73.6\%) of these patients were women (Table 1). The mean $( \pm S D)$ duration of disease at the end of the followup period was $17.1 \pm 13.2$ years. At some point during the course of their disease, 231 patients (58.6\%) received one or more disease-modifying treatments: interferon beta (36.5\%), azathioprine (23.1\%), mitoxantrone (12.9\%), cyclophosphamide (7.1\%), methotrexate (7.1\%), glatiramer acetate (3.5\%) and mycophenolate mofetil (1.3\%). The patients had received azathioprine for an average of 8.6 years and interferon beta for an average of 10.6 years after the onset of the disease.

\section{Onset of Disease}

The mean age at the onset of multiple sclerosis was $13.7 \pm 2.4$ years. Onset occurred at the age of 10 years or younger in 30 patients $(7.6 \%)$, at 12 years or younger in 71 patients $(18.0 \%)$, and at 14 years or younger in 159 patients (40.4\%). Encephalitic signs, such as headache, vomiting, seizures, or disorders of consciousness, were present in 29 patients $(7.4 \%)$. The initial course was exacerbating-remitting in all except nine patients (2.3\%) who had a progressive initial course; these nine patients were all over 13 years of age at onset.

\section{Course of Disease}

The estimated median time between the first two neurologic episodes was 2.0 years. Among the 385 patients with an exacerbating-remitting initial course, 110 (28.6\%) converted to secondary progression during follow-up. The estimated median time from the onset of multiple sclerosis to conversion to secondary progression was 28.1 years (95\% confidence interval [CI], 25.0 to 32.1) (Fig. 1A). The estimated median age at conversion to secondary progression was 41.4 years $(95 \% \mathrm{CI}$, 37.8 to 45.7 ) (Fig. 1B).

\section{Time to Development of Irreversible Disability}

The estimated median times from the onset of multiple sclerosis to the assignment of DSS scores of 4,6 , and 7 were 20.0 years (95\% CI, 19.0 to 22.4), 28.9 years ( $95 \% \mathrm{CI}, 27.0$ to 33.0 ), and 37.0 years (95\% CI, 34.0 to 42.2 ), respectively. These time intervals were longer for patients who were 12 years of age or younger at the onset of multiple sclerosis. However, the difference between those who were 12 years of age or younger and those who were older than 12 years at onset was significant only for time to a DSS score of 4 (median, 28.0 years [95\% CI, 21.0 to 31.6] vs. 19.1 years [95\% CI, 16.2 to 21.0]; $\mathrm{P}=0.02$ ). 


\begin{tabular}{|c|c|c|c|c|}
\hline Characteristic & $\begin{array}{l}\text { All Patients } \\
(\mathrm{N}=394)\end{array}$ & $\begin{array}{l}\text { Onset at } \leq 12 \mathrm{Yr} \\
\qquad(\mathrm{N}=71)\end{array}$ & $\begin{array}{l}\text { Onset at }>12 \mathrm{Yr} \\
\quad(\mathrm{N}=323)\end{array}$ & P Value \\
\hline Sex - no. (\%) & & & & 0.4 \\
\hline Male & $104(26.4)$ & $22(31.0)$ & $82(25.4)$ & \\
\hline Female & $290(73.6)$ & $49(69.0)$ & $241(74.6)$ & \\
\hline Diagnosis — no. (\%) $†$ & & & & 0.5 \\
\hline Clinically definite & $297(75.4)$ & $52(73.2)$ & 245 (75.9) & \\
\hline Laboratory-supported definite & $29(7.4)$ & $4(5.6)$ & $25(7.7)$ & \\
\hline Clinically probable & $65(16.5)$ & $15(21.1)$ & $50(15.5)$ & \\
\hline Laboratory-supported probable & $3(0.8)$ & 0 & $3(0.9)$ & \\
\hline Familial history of multiple sclerosis — no. (\%) & & & & 0.8 \\
\hline Yes & $53(13.5)$ & $7(9.9)$ & $46(14.2)$ & \\
\hline No & $328(83.2)$ & $61(85.9)$ & $267(82.7)$ & \\
\hline Unknown & $13(3.3)$ & $3(4.2)$ & $10(3.1)$ & \\
\hline \multicolumn{5}{|l|}{ Age at onset of multiple sclerosis $-\mathrm{yr}$} \\
\hline Mean & $13.7 \pm 2.4$ & $9.5 \pm 2.3$ & $14.6 \pm 1.1$ & $<0.001$ \\
\hline Median & 14.5 & 10.3 & 14.9 & \\
\hline Range & $1.5-16.0$ & $1.5-11.9$ & $12.1-16.0$ & \\
\hline Initial symptoms - no. (\%) & & & & 0.9 \\
\hline Isolated optic neuritis & $92(23.4)$ & $18(25.4)$ & $74(22.9)$ & \\
\hline Isolated brain-stem symptoms & $66(16.8)$ & $14(19.7)$ & $52(16.1)$ & \\
\hline Isolated long-tract symptoms & $149(37.8)$ & $23(32.4)$ & $126(39.0)$ & \\
\hline Other symptoms or combination of symptoms & $87(22.1)$ & $16(22.5)$ & $71(22.0)$ & \\
\hline Initial course of multiple sclerosis - no. (\%) & & & & 0.4 \\
\hline Exacerbating-remitting & $385(97.7)$ & $71(100)$ & $314(97.2)$ & \\
\hline Progressive & $9(2.3)$ & 0 & $9(2.8)$ & \\
\hline \multicolumn{5}{|l|}{$\begin{array}{l}\text { Kaplan-Meier estimate of time between first } \\
2 \text { relapses }-y r\end{array}$} \\
\hline Mean & $5.0 \pm 0.4$ & $7.3 \pm 1.0$ & $4.5 \pm 0.4$ & 0.005 \\
\hline Median & 2.0 & 4.6 & 2.0 & \\
\hline Range & $0-40.8$ & $0-40.1$ & $0-40.8$ & \\
\hline \multicolumn{5}{|l|}{ No. of relapses during the first 2 yrt? } \\
\hline Mean & $1.9 \pm 1.4$ & $1.6 \pm 0.9$ & $2.0 \pm 1.5$ & 0.04 \\
\hline Median & 1 & 1 & 1 & \\
\hline Range & $1-10$ & $1-4$ & $1-10$ & \\
\hline \multicolumn{5}{|l|}{ Duration of multiple sclerosis at last follow-up - yr } \\
\hline Mean & $17.1 \pm 13.2$ & $22.6 \pm 15.6$ & $15.8 \pm 12.3$ & $<0.001$ \\
\hline Median & 15.0 & 20.9 & 14.1 & \\
\hline Range & $0.01-69.04$ & $0.20-69.04$ & $0.01-60.51$ & \\
\hline
\end{tabular}


When the time of onset of multiple sclerosis was used as the reference time in multivariate analysis, the nature of the initial course was the only significant prognostic factor: a progressive onset was associated with shorter times to reach irreversible disability (Table 2). At the time of the second neurologic episode, the time interval between the first two neurologic episodes did not show any consistent effect on the time to reach irreversible disability. Two years after onset, the main prognostic factor remained a progressive course at onset. The other significant prognostic factor was the number of relapses during the first 2 years of the disease, with each additional relapse increasing the rate of disability by 31 to $41 \%$. Age at onset of multiple sclerosis was not a prognostic factor for time to development of disability, either as a continuous variable or as a categorical variable with cutoff at 10 or 12 years (data not shown). The neurologic department at which the patient was seen did not influence the time to development of irreversible disability in any analysis (data not shown).

\section{Age at Development of Irreversible Disability}

The estimated median ages at assignment of DSS scores of 4, 6, and 7 were 34.6 years ( $95 \%$ CI, 31.2 to 36.0), 42.2 years ( $95 \%$ CI, 40.5 to 46.9$)$, and 50.5 years (95\% CI, 47.1 to 64.8$)$, respectively. The only significant prognostic factor for age at development of irreversible disability was the initial course of the disease: a progressive initial course was associated with a younger age of development of disability (adjusted hazard ratios, 2.94 [95\% CI, 1.34 to 6.42] for a DSS score of 4, 4.48 [95\% CI, 2.01 to 10.00$]$ for a DSS score of 6 , and 3.13 [95\% CI, 1.18 to 8.28] for a DSS score of 7).

\section{COMPARISON OF CHILDHOOD-ONSET AND ADULT- ONSET MULTIPLE SCLEROSIS}

\section{Patient Characteristics}

The cohort of patients with adult-onset multiple sclerosis included 1775 patients, $64.1 \%$ of whom were women. The mean age at onset of multiple sclerosis was 32.2 \pm 9.9 years (median, 30.8), and the mean duration of disease was $11.5 \pm 9.3$ years (median, 9.7). The female:male ratio was higher in the childhood-onset cohort than in the adultonset cohort ( 2.8 vs. $1.8, \mathrm{P}<0.001)$.

\section{Onset of Disease}

Isolated optic neuritis and isolated brain-stem dysfunction were more frequent, and isolated dysfunction of long tracts was less frequent, in patients with childhood-onset multiple sclerosis than in patients with adult-onset multiple sclerosis (23.4\%, $16.8 \%$, and $37.8 \%$, respectively, vs. $17.9 \%$, $8.5 \%$, and $52.9 \%$, respectively; $\mathrm{P}<0.001)$. Encephalitic symptoms were observed in $7 \%$ of patients with childhood-onset disease and were virtually absent in patients with adult-onset disease. The initial course of multiple sclerosis was more often exacerbating-remitting in patients with childhoodonset multiple sclerosis than in patients with adult-onset disease $(97.7 \%$ vs. $84.3 \%, \mathrm{P}<0.001)$.

\section{Course of Disease}

The estimated median time from the onset of multiple sclerosis to the second neurologic episode did not differ significantly between patients with childhood-onset and those with adult-onset disease ( 2.0 vs. 2.2 years, $P=0.2$ ). The estimated median time to conversion to secondary progression was approximately 10 years longer $(\mathrm{P}<0.001)$, and the estimated median age at conversion to secondary progression was approximately 10 years younger $(\mathrm{P}<0.001)$, in patients with childhoodonset disease than in patients with adult-onset disease (Fig. 1).

\section{Time to Development of Irreversible Disability}

As shown in Figure 1, the estimated median times to assignment of DSS scores of 4, 6, and 7 were approximately 10 years longer in patients with childhood-onset multiple sclerosis than in patients with adult-onset multiple sclerosis $(\mathrm{P}<0.001$ for all comparisons). Once a score of 4 was attained, the median time to reach a score of 6 was 6.0 years (95\% CI, 5.0 to 7.0) for patients with childhoodonset disease and 5.7 years (95\% CI, 5.0 to 6.4) for those with adult-onset disease $(\mathrm{P}=0.4)$. Similarly, after a score of 6 was reached, the median time to reach a score of 7 was 4.9 years (95\% CI, 3.5 to 6.5 ) for patients with childhood-onset disease, as compared with 3.4 years ( $95 \% \mathrm{CI}, 3.0$ to 4.0 ) for patients with adult-onset disease $(\mathrm{P}=0.2)$. The median time to reach a score of 7 once a score of 4 was reached was 12.2 years (95\% CI, 10.7 to 15.6) for patients with childhood-onset disease and 12.2 
years (95\% CI, 11.0 to 14.7$)$ for patients with adultonset disease $(\mathrm{P}=0.8)$.

Age at Development of Irreversible Disability

On average, patients with childhood-onset disease reached DSS scores of 4, 6, and 7 at an estimated median age 10 years younger than did patients with adult-onset disease $(\mathrm{P}<0.001$ for all comparisons) (Fig. 1).

\section{I S C USSION}

This large, collaborative, multicenter, observational study revealed several distinctive features of childhood-onset multiple sclerosis. The female: male ratio was high (2.8). The initial course of the disease was exacerbating-remitting in $98 \%$ of the patients. The estimated median time from onset of disease to conversion to secondary progression was 28 years, and the median age at conversion was 41 years. The estimated median times from the onset of multiple sclerosis to the assignment of DSS scores of 4, 6, and 7 were 20.0, 28.9, and 37.0 years, respectively, and the corresponding estimated median ages were $34.6,42.2$, and 50.5 years. In comparison with a representative cohort of patients with adult-onset multiple sclerosis, the patients with childhood-onset multiple sclerosis were more likely to be female; were more likely to have isolated optic neuritis, isolated brain-stem syndrome, or encephalitic symptoms at presentation; were more likely to have an exacerbating-remitting initial course of the disease; and took 10 years longer to convert to secondary progression and to reach disability landmarks but did so at an age 10 years younger.

All patients were recruited from the French and Belgian EDMUS network. In France, this network covers the entire country uniformly and includes all departments of adult neurology with acknowledged interest in the care of patients with multiple sclerosis. Each of the 13 participating departments acts as a referral center for multiple sclerosis in its area, and case acquisition is performed in a similar manner in all of them.

A potential source of selection bias could have been that some patients with childhood-onset multiple sclerosis may not have been seen in adult neurology departments because they had either very severe disease, leading to death before adulthood, or very benign disease, requiring no specialized consultation during adulthood. We think
Figure 1 (facing page). Kaplan-Meier Estimates of the Time to (Panel A) and the Age at (Panel B) Conversion to Secondary Progression and of the Time to (Panels C, $E$, and G) and the Age at (Panels D, F, and H) Assignment of Scores According to the Kurtzke Disability Status Scale (DSS), among Patients with Childhood-Onset and Those with Adult-Onset Multiple Sclerosis.

Panels $A$ and $B$ refer to the subgroup of patients with an exacerbating-remitting initial course of multiple sclerosis (385 patients with childhood-onset disease and 1496 patients with adult-onset disease). Panels $C$ through $\mathrm{H}$ refer to the entire population of patients with multiple sclerosis (394 with childhood-onset disease and 1775 with adult-onset disease). Panels A, C, E, and $G$ include median number of years and $95 \%$ confidence intervals, and Panels B, D, F, and $\mathrm{H}$ include median age and $95 \%$ confidence intervals. Irreversibledisability scores on the $\mathrm{DSS}^{24,25}$ range from 0 to 10 , with higher scores indicating more severe disability. A score of 4 indicates limited walking ability but the ability to walk more than $500 \mathrm{~m}$ without assistance and without resting, 6 indicates the ability to walk with unilateral support no more than $100 \mathrm{~m}$ without resting, and 7 indicates the ability to walk no more than $10 \mathrm{~m}$ without resting while using a wall or furniture for support.

both situations are rare. When we looked at our cohort of patients with childhood-onset multiple sclerosis, we did not find that the center had any effect on the outcome. In the Lyon EDMUS database, which contributed 34\% of the cohort with childhood-onset multiple sclerosis and the entire cohort with adult-onset disease, case acquisition and data collection have been performed simultaneously and similarly for childhood-onset and adult-onset cases since 1976.

Another potential source of bias is that the presence of optic neuritis might be more likely to lead to a diagnosis of multiple sclerosis than would the presence of other neurologic symptoms. However, for this bias to occur, the probability of a diagnosis of multiple sclerosis in patients with optic neuritis must be higher in only one study group; if the diagnosis is more likely in both child and adult patients with optic neuritis at the onset of disease, then there is no potential for bias. Even if a diagnosis of multiple sclerosis were more likely in patients with childhood-onset multiple sclerosis presenting with optic neuritis, the presence of symptoms other than optic neuritis at onset would probably only delay the time to the diagnosis of multiple sclerosis and not reduce the probability of the diagnosis itself. Because our study recruited patients 


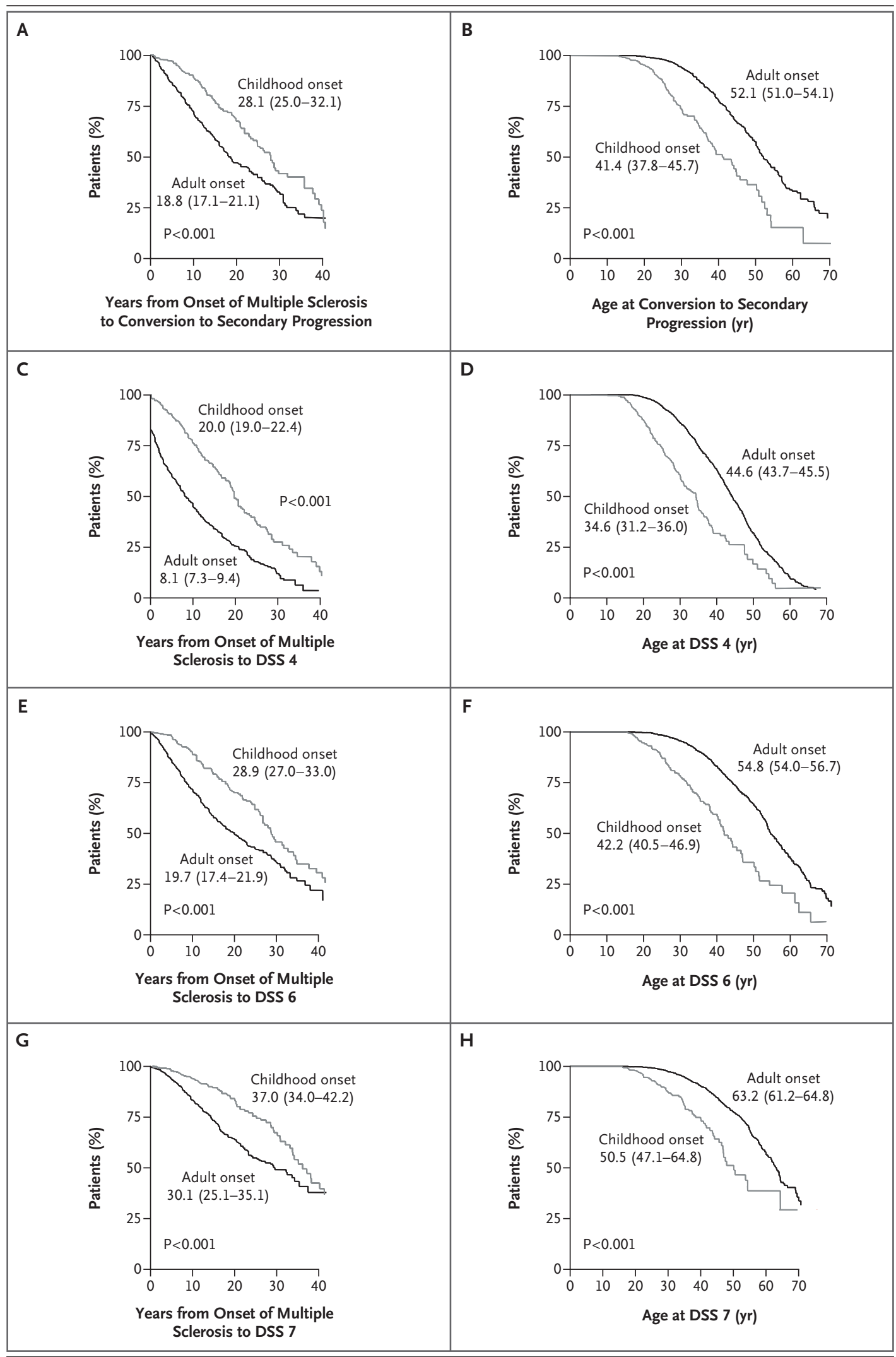




\begin{tabular}{|c|c|c|c|c|c|c|}
\hline \multirow[t]{2}{*}{ Variable } & \multicolumn{2}{|c|}{ DSS 4} & \multicolumn{2}{|c|}{ DSS 6} & \multicolumn{2}{|c|}{ DSS 7} \\
\hline & $\begin{array}{l}\text { Crude Hazard } \\
\text { Ratio }\end{array}$ & $\begin{array}{l}\text { Adjusted Hazard } \\
\text { Ratio }(95 \% \mathrm{Cl})\end{array}$ & $\begin{array}{l}\text { Crude Hazard } \\
\text { Ratio }\end{array}$ & $\begin{array}{l}\text { Adjusted Hazard } \\
\text { Ratio }(95 \% \mathrm{Cl})\end{array}$ & $\begin{array}{l}\text { Crude Hazard } \\
\text { Ratio }\end{array}$ & $\begin{array}{l}\text { Adjusted Hazard } \\
\text { Ratio }(95 \% \mathrm{Cl})\end{array}$ \\
\hline \multicolumn{7}{|l|}{ Date at onset of multiple sclerosis } \\
\hline Age at onset & 1.06 & $1.04(0.98-1.12)$ & 1.05 & $1.04(0.96-1.12)$ & 1.04 & $1.00(0.92-1.09)$ \\
\hline Female sex & 1.10 & $1.09(0.75-1.57)$ & 1.02 & $1.02(0.66-1.58)$ & 0.81 & $0.79(0.46-1.34)$ \\
\hline Progressive course at onset & 3.10 & $2.96(1.36-6.49)$ & 5.32 & $4.76(2.13-10.64)$ & 3.67 & $3.13(1.18-8.30)$ \\
\hline \multicolumn{7}{|l|}{ Symptoms at onset } \\
\hline \multicolumn{7}{|l|}{ Isolated optic neuritis (reference) } \\
\hline $\begin{array}{l}\text { Isolated brain-stem symp- } \\
\text { toms }\end{array}$ & 1.07 & $1.09(0.67-1.77)$ & 0.89 & $0.91(0.49-1.70)$ & 0.94 & $0.96(0.45-2.03)$ \\
\hline Isolated long-tract symptoms & 0.87 & $0.84(0.56-1.26)$ & 0.98 & $0.94(0.58-1.53)$ & 1.00 & $0.97(0.54-1.74)$ \\
\hline $\begin{array}{l}\text { Other symptoms or combi- } \\
\text { nation of symptoms }\end{array}$ & 1.05 & $0.99(0.60-1.63)$ & 1.34 & $1.29(0.74-2.25)$ & 0.84 & $0.67(0.31-1.42)$ \\
\hline $\begin{array}{l}\text { Decade of onset of multiple } \\
\text { sclerosis }\end{array}$ & 1.21 & $1.17(1.00-1.36)$ & 1.28 & $1.22(1.00-1.48)$ & 1.37 & $1.37(1.06-1.77)$ \\
\hline \multicolumn{7}{|l|}{$\begin{array}{l}\text { Date at second episode of multiple } \\
\text { sclerosis }\end{array}$} \\
\hline Age at onset & 1.03 & $1.03(0.96-1.10)$ & 1.00 & $1.00(0.93-1.08)$ & 0.99 & $0.98(0.89-1.08)$ \\
\hline Female sex & 1.18 & $1.08(0.72-1.62)$ & 1.07 & $1.00(0.62-1.62)$ & 0.81 & $0.68(0.39-1.19)$ \\
\hline \multicolumn{7}{|l|}{$\begin{array}{l}\text { Interval between 1st and 2nd } \\
\text { episodes }\end{array}$} \\
\hline \multicolumn{7}{|l|}{$\leq 2 \mathrm{yr}$ (reference) } \\
\hline $2-6 y r$ & 0.80 & $0.72(0.46-1.13)$ & 0.78 & $0.74(0.44-1.25)$ & 0.46 & $0.38(0.18-0.78)$ \\
\hline$>6 \mathrm{yr}$ & 1.04 & $0.91(0.56-1.47)$ & 1.28 & $1.21(0.70-2.11)$ & 1.29 & $1.19(0.61-2.31)$ \\
\hline \multicolumn{7}{|l|}{ Symptoms at onset } \\
\hline \multicolumn{7}{|l|}{$\begin{array}{l}\text { Isolated optic neuritis } \\
\text { (reference) }\end{array}$} \\
\hline $\begin{array}{l}\text { Isolated brain-stem symp- } \\
\text { toms }\end{array}$ & 0.66 & $0.69(0.41-1.15)$ & 0.61 & $0.64(0.33-1.23)$ & 0.68 & $0.67(0.31-1.47)$ \\
\hline Isolated long-tract symptoms & 0.58 & $0.58(0.38-0.88)$ & 0.72 & $0.68(0.41-1.13)$ & 0.69 & $0.53(0.28-1.01)$ \\
\hline $\begin{array}{l}\text { Other symptoms or combi- } \\
\text { nation of symptoms }\end{array}$ & 0.63 & $0.65(0.38-1.11)$ & 0.87 & $0.88(0.48-1.60)$ & 0.61 & $0.46(0.21-1.01)$ \\
\hline $\begin{array}{l}\text { Decade of onset of multiple } \\
\text { sclerosis }\end{array}$ & 0.98 & $0.94(0.80-1.10)$ & 0.95 & $0.96(0.80-1.16)$ & 0.97 & $1.04(0.81-1.33)$ \\
\hline
\end{tabular}

with childhood-onset multiple sclerosis from departments of adult neurology, we included patients with a long duration of disease. Regardless of the symptoms at onset and the delay in diagnosis resulting from the initial presentation, all patients with childhood-onset multiple sclerosis were probably captured in our cohort. The likelihood that the presence of initial symptoms of optic neuritis led to a differential selection bias is therefore very low.

All participating centers used the EDMUS soft- ware with a standardized common language for each patient, thus producing a high level of homogeneity in the definition of clinical measures. ${ }^{26}$ To ensure accuracy of the descriptions of initial disease presentation, we consulted the pediatricdepartment records of patients with childhoodonset disease whenever possible. Furthermore, records from departments of adult neurology were systematically reviewed for the current study.

About half of our patients with childhoodonset multiple sclerosis received immunoactive 


\begin{tabular}{|c|c|c|c|c|c|c|}
\hline \multirow[t]{2}{*}{ Variable } & \multicolumn{2}{|c|}{ DSS 4} & \multicolumn{2}{|c|}{ DSS 6} & \multicolumn{2}{|c|}{ DSS 7} \\
\hline & $\begin{array}{l}\text { Crude Hazard } \\
\text { Ratio }\end{array}$ & $\begin{array}{l}\text { Adjusted Hazard } \\
\text { Ratio }(95 \% \mathrm{Cl})\end{array}$ & $\begin{array}{l}\text { Crude Hazard } \\
\text { Ratio }\end{array}$ & $\begin{array}{l}\text { Adjusted Hazard } \\
\text { Ratio }(95 \% \mathrm{Cl})\end{array}$ & $\begin{array}{l}\text { Crude Hazard } \\
\text { Ratio }\end{array}$ & $\begin{array}{l}\text { Adjusted Hazard } \\
\text { Ratio }(95 \% \mathrm{Cl})\end{array}$ \\
\hline \multicolumn{7}{|l|}{$\begin{array}{l}2 \text { Yr after onset of multiple } \\
\text { sclerosis: }\end{array}$} \\
\hline Age at onset & 1.07 & $1.04(0.96-1.11)$ & 1.05 & $1.03(0.96-1.11)$ & 1.04 & $1.00(0.91-1.09)$ \\
\hline Female sex & 1.13 & $1.07(0.72-1.58)$ & 0.99 & $0.94(0.61-1.46)$ & 0.79 & $0.73(0.43-1.25)$ \\
\hline Progressive course at onset & 3.56 & $4.40(1.96-9.88)$ & 5.53 & $6.34(2.76-14.61)$ & 3.74 & $4.43(1.61-12.19)$ \\
\hline No. of relapses during lst $2 \mathrm{yr}$ & 1.36 & $1.33(1.16-1.54)$ & 1.32 & $1.31(1.10-1.56)$ & 1.37 & $1.41(1.13-1.76)$ \\
\hline \multicolumn{7}{|l|}{ Symptoms at onset } \\
\hline \multicolumn{7}{|l|}{ Isolated optic neuritis (reference) } \\
\hline $\begin{array}{l}\text { Isolated brain-stem symp- } \\
\text { toms }\end{array}$ & 0.97 & $0.91(0.54-1.51)$ & 0.84 & $0.78(0.41-1.48)$ & 0.94 & $0.87(0.40-1.86)$ \\
\hline Isolated long-tract symptoms & 0.78 & $0.71(0.47-1.09)$ & 0.98 & $0.88(0.54-1.44)$ & 1.00 & $0.88(0.48-1.59)$ \\
\hline $\begin{array}{l}\text { Other symptoms or combi- } \\
\text { nation of symptoms }\end{array}$ & 0.93 & $0.76(0.45-1.29)$ & 1.29 & $1.05(0.59-1.87)$ & 0.78 & $0.47(0.21-1.06)$ \\
\hline $\begin{array}{l}\text { Decade of onset of multiple } \\
\text { sclerosis }\end{array}$ & 1.31 & $1.18(0.99-1.40)$ & 1.31 & $1.17(0.96-1.44)$ & 1.40 & $1.30(0.99-1.70)$ \\
\hline
\end{tabular}

* Scores on the Kurtzke Disability Status Scale (DSS) ${ }^{24,25}$ range from 0 to 10 , with higher scores indicating more severe disability. A score of 4 indicates limited walking ability but the ability to walk more than $500 \mathrm{~m}$ without assistance and without resting; a score of 6 indicates the ability to walk only with unilateral support and no more than $100 \mathrm{~m}$ without resting; and a score of 7 indicates the ability to walk no more than $10 \mathrm{~m}$ without resting while using a wall or furniture for support. All analyses were adjusted for age at onset of disease, sex, symptoms at onset, and decade during which the onset occurred. For the analyses with onset of multiple sclerosis as the reference time, adjustments were also made for the initial course of the disease. For the analyses with a second episode of multiple sclerosis as the reference time, adjustments were also made for the interval between the first and the second episodes. For the analyses with 2 years after onset of multiple sclerosis as the reference time, adjustments were also made for the initial course of the disease and the number of relapses during these 2 years. $\mathrm{Cl}$ denotes confidence interval.

$\uparrow$ For the category of DSS 4, the data are from the 347 patients with an exacerbating-remitting onset of disease, a second neurologic episode, and no occurrence of a DSS score of 4 before the second episode. For the category of DSS 6, the data are from the 367 patients with an exacerbating-remitting onset of disease, a second neurologic episode, and no occurrence of a DSS score of 6 before the second episode. For the category of DSS 7, the data are from the 367 patients with an exacerbating-remitting onset of disease, a second neurologic episode, and no occurrence of a DSS score of 7 before the second episode.

$\$$ For the category of DSS 4, the data are from the 329 patients followed for at least 2 years after the onset of disease with no occurrence of a DSS score of 4 during these 2 years. For the category of DSS 6, the data are from the 352 patients followed for at least 2 years after the onset of disease with no occurrence of a DSS score of 6 during these 2 years. For the category of DSS 7, the data are from the 353 patients followed for at least 2 years after the onset of disease with no occurrence of a DSS score of 7 during these 2 years.

drugs. None of these drugs has a proven effect on the long-term development of disability. ${ }^{27}$ The treatments were usually given a long time after the onset of multiple sclerosis and therefore could not have modified the early course of the disease. However, we cannot definitively rule out an effect of treatment on the long-term course of the disease. That said, treated patients had more severe disease than untreated patients, and removing them from the analysis would have led to overestimation of the times to development of irreversible disability. Data on patients with adultonset disease were taken from the Lyon EDMUS database, which was locked in April 1997 at a time when almost no patients received currently acknowledged disease-modifying therapies. ${ }^{18-21}$ About half of these patients received azathioprine at some point during the course of their disease, mainly during the relapsing-remitting phase, and not before the third relapse. Azathioprine has no proven effect on the development of irreversible disability in multiple sclerosis. ${ }^{28}$

Our results are consistent with those of other studies of childhood-onset multiple sclerosis from departments of adult neurology with regard to onset, course, prognosis, and clinical predictors of disability, $111-14,29-31$ and in particular with regard to times to development of secondary progression and irreversible disability ${ }^{14}$ and the ages at which these events occur. ${ }^{11}$ Our results are also 
consistent with those from the group recruited from pediatric neurology departments in the Kids with Multiple Sclerosis (KIDMUS) study, which included 296 children with a first episode of acute inflammatory demyelination of the central nervous system seen in French pediatric neurology departments. ${ }^{15,32,33}$ Furthermore, the Lyon Natural History Multiple Sclerosis Cohort, from which our cohort of patients with adult-onset multiple sclerosis was extracted, has already been described extensively, ${ }^{1,18-21}$ with results consistent with those from other major cohorts. ${ }^{34-36}$ For these reasons, we think the present results, drawn entirely from one region of Europe, can be generalized to other populations.

In conclusion, despite a slower development of irreversible disability, patients with childhood- onset multiple sclerosis reach secondary-progression and disability milestones at ages approximately 10 years younger than do patients with adult-onset disease. Efforts to improve therapy for multiple sclerosis have focused on the population with adult-onset disease. Patients with childhood-onset multiple sclerosis clearly deserve similar attention.

Supported by funds from the Société Française de Neurologie, the Région Rhône-Alpes, the Ligue Française contre la Sclérose en Plaques, the Association pour la Recherche sur la Sclérose en Plaques, and the Canadian Institutes of Health Research (CIHR). Samy Suissa is the recipient of a Distinguished Scientist award from the CIHR.

No potential conflict of interest relevant to this article was reported.

We thank the patients for their participation in the study, Mr. Abbas Kezouh for statistical advice, Dr. Romain Marignier for helpful discussions about the paper, and Mrs. Isabelle Pairel for assistance in the preparation of the manuscript.

APPENDIX

In addition to the authors, the following investigators participated to the Adult Neurology Departments KIDMUS study: Hôpital Pellegrin, Bordeaux, France - H. Brochet, J.C. Ouallet; Hôpital Général, Dijon, France - G. Couvreur, A. Fromont; University Hospital Gasthuisberg, Leuven, Belgium - O. Deryck, P. Ketelaer; Hôpital Roger Salengro, Lille, France - H. Zéphir; Hôpital Neurologique Pierre Wertheimer, Lyon, France - I. Ionescu-Achiti; Hôpital de La Timone, Marseille, France - B. Chabrol, J. Mancini, I. Malikova; Hôpital Saint Julien, Nancy, France - S. PittionVouyovitch; Hôpital de la Pitié-Salpêtrière, Paris - B. Fontaine, O. Lyon-Caen, S. Mrejen, B. Stankoff, A. Tourbah; Hôpital Pontchaillou, Rennes, France - M. Coustans, E. Le Page, E. Leray; Hôpital Purpan, Toulouse, France - D. Brassat, G. Lau.

REFERENCES

1. Confavreux C, Aimard G, Devic M. Course and prognosis of multiple sclerosis assessed by the computerized data processing of 349 patients. Brain 1980;103: 281-300.

2. Müller R. Course and prognosis of disseminated sclerosis in relation to age of onset. Arch Neurol Psychiatry 1951;66: 561-70.

3. Gall JC Jr, Hayles AB, Siekert RG, Keith HM. Multiple sclerosis in children: a clinical study of 40 cases with onset in childhood. Pediatrics 1958;21:703-9.

4. Boutin B, Esquivel E, Mayer M, Chaumet S, Ponsot G, Arthuis M. Multiple sclerosis in children: report of clinical and paraclinical features of 19 cases. Neuropediatrics 1988;19:118-23.

5. Hanefeld F, Bauer HJ, Christen HJ, Kruse B, Bruhn H, Frahm J. Multiple sclerosis in childhood: report of 15 cases. Brain Dev 1991;13:410-6.

6. Sindern E, Haas J, Stark E, Wurster U. Early onset MS under the age of 16: clini$\mathrm{cal}$ and paraclinical features. Acta Neurol Scand 1992;86:280-4.

7. Guilhoto LM, Osorio CA, Machado LR, et al. Pediatric multiple sclerosis: report of 14 cases. Brain Dev 1995;17:9-12.

8. Cole GF, Stuart CA. A long perspective on childhood multiple sclerosis. Dev Med Child Neurol 1995;37:661-6.
9. Selcen D, Anlar B, Renda Y. Multiple sclerosis in childhood: report of 16 cases. Eur Neurol 1996;36:79-84.

10. Ruggieri M, Polizzi A, Pavone L, Grimaldi LM. Multiple sclerosis in children under 6 years of age. Neurology 1999;53: 478-84.

11. Simone IL, Carrara D, Tortorella C, et al. Course and prognosis in early-onse MS: comparison with adult-onset forms. Neurology 2002;59:1922-8.

12. Duquette P, Murray TJ, Pleines J, et al. Multiple sclerosis in childhood: clinical profile in 125 patients. J Pediatr 1987;111: 359-63.

13. Ghezzi A, Deplano V, Faroni J, et al. Multiple sclerosis in childhood: clinical features of 149 cases. Mult Scler 1997;3: 43-6.

14. Boiko A, Vorobeychik G, Paty D, Devonshire V, Sadovnick D. Early onset multiple sclerosis: a longitudinal study. Neurology 2002;59:1006-10.

15. Mikaeloff Y, Caridade G, Assi S, Suissa $S$, Tardieu M. Prognostic factors for early severity in a childhood multiple sclerosis cohort. Pediatrics 2006;118:1133-9.

16. Confavreux C, Compston DAS, Hommes OR, McDonald WI, Thompson AJ. EDMUS, a European database for multiple sclerosis. J Neurol Neurosurg Psychiatry 1992;55:671-6.
17. Poser CM, Paty DW, Scheinberg L, et al. New diagnostic criteria for multiple sclerosis: guidelines for research protocols. Ann Neurol 1983;13:227-31.

18. Confavreux C, Vukusic S, Moreau T, Adeleine P. Relapses and progression of disability in multiple sclerosis. $\mathrm{N}$ Engl $\mathrm{J}$ Med 2000;343:1430-8.

19. Confavreux C, Vukusic S, Adeleine P. Early clinical predictors and progression of irreversible disability in multiple sclerosis: an amnesic process. Brain 2003;126: 770-82.

20. Confavreux C, Vukusic S. Age at disability milestones in multiple sclerosis. Brain 2006;129:595-605.

21. Idem. Natural history of multiple sclerosis: a unifying concept. Brain 2006;129: 606-16.

22. Schumacher GA, Beebe G, Kibler RF, et al. Problems of experimental trials of therapy in multiple sclerosis: report by the Panel on the Evaluation of Experimental Trials of Therapy in Multiple Sclerosis. Ann N Y Acad Sci 1965;122:552-68.

23. Lublin FD, Reingold SC. Defining the clinical course of multiple sclerosis: results of an international survey. Neurology 1996;46:907-11.

24. Kurtzke JF. On the evaluation of disability in multiple sclerosis. Neurology 1961;11:686-94. 
25. Idem. Rating neurologic impairment in multiple sclerosis: an Expanded Disability Status Scale (EDSS). Neurology 1983; 33:1444-52.

26. Amato MP, Grimaud J, Achiti I, et al. European validation of a standardized clinical description of multiple sclerosis. J Neurol 2004;251:1472-80.

27. Compston A, Coles A. Multiple sclerosis. Lancet 2002;359:1221-31. [Erratum, Lancet 2002;360:648.]

28. Yudkin PL, Ellison GW, Ghezzi A, et al. Overview of azathioprine treatment in multiple sclerosis. Lancet 1991;338:1051-5.

29. Ghezzi A, Pozzilli C, Liguori M, et al. Prospective study of multiple sclerosis with early onset. Mult Scler 2002;8:115-8.
30. Bye AM, Kendall B, Wilson J. Multiple sclerosis in childhood: a new look. Dev Med Child Neurol 1985;27:215-22.

31. Ozakbas S, Idiman E, Baklan B, Yulug B. Childhood and juvenile onset multiple sclerosis: clinical and paraclinical features. Brain Dev 2003;25:233-6.

32. Mikaeloff Y, Suissa S, Vallee L, et al. First episode of acute CNS inflammatory demyelination in childhood: prognostic factors for multiple sclerosis and disability. J Pediatr 2004;144:246-52.

33. MikaeloffY, Adamsbaum C, Husson B, et al. MRI prognostic factors for relapse after acute CNS inflammatory demyelination in childhood. Brain 2004;127:1942-7.

34. Weinshenker BG, Bass B, Rice GP, et al. The natural history of multiple sclerosis: a geographically based study. I. Clinical course and disability. Brain 1989;112: 133-46.

35. Runmarker B, Andersen O. Prognostic factors in a multiple sclerosis incidence cohort with twenty-five years of follow-up. Brain 1993;116:117-34.

36. Confavreux C, Compston A. The natural history of multiple sclerosis. In: Compston A, Confavreux C, Lassmann $\mathrm{H}$, et al., eds. McAlpine's multiple sclerosis. 4th ed. Philadelphia: Churchill Livingstone, 2006: 183-272.

Copyright @ 2007 Massachusetts Medical Society.

FULL TEXT OF ALL JOURNAL ARTICLES ON THE WORLD WIDE WEB

Access to the complete text of the Journal on the Internet is free to all subscribers. To use this Web site, subscribers should go to the Journal's home page (www.nejm.org) and register by entering their names and subscriber numbers as they appear on their mailing labels. After this one-time registration, subscribers can use their passwords to log on for electronic access to the entire Journal from any computer that is connected to the Internet. Features include a library of all issues since January 1993 and abstracts since January 1975, a full-text search capacity, and a personal archive for saving articles and search results of interest. All articles can be printed in a format that is virtually identical to that of the typeset pages. Beginning 6 months after publication, the full text of all Original Articles and Special Articles is available free to nonsubscribers who have completed a brief registration. 